\title{
Accuracy of Global Microirrigation Distribution Uniformity Estimates
}

\author{
Stuart W. Styles ${ }^{1}$; Charles M. Burt ${ }^{2}$; Franklin Gaudi ${ }^{3}$; and Sierra Orvis ${ }^{4}$
}

\begin{abstract}
Emitter pressures and flow rates were systematically and extensively sampled in one drip and one microspray field. The data distributions are presented. The accuracy of rapid (limited samples) evaluation pressure sampling procedures was found to be quite good if the pressure distribution was systematic, but erroneous if the pressure distribution throughout a field was random. A simple mathematical combination of two nonuniformity components (due to pressure differences, and other causes of flow variation) provided a better estimate of overall system distribution uniformity than more complex mathematics.
\end{abstract}

\section{Introduction}

The Cal Poly Irrigation Training and Research Center (ITRC) software and procedure for the rapid evaluation of drip and microirrigation systems (Burt 2004; Burt et al. 1992) has been widely used in California by mobile laboratories, consultants, and others. Evaluation procedures developed by others are described by Burt (2004).

The ITRC rapid procedure uses limited sampling to estimate a field's distribution uniformity (DU) with about 1 person/day of field work. Programs that use this procedure are popular with farmers because the evaluations clearly show the locations and relative magnitudes of problems due to plugging and pressure differences between emitters. The evaluation procedure also defines the relative importance of various problems, plus it gives an estimate of the field DU. There is no doubt in the writers' minds that the rapid evaluation procedure provides a benefit to farmers.

The research that is reported in this paper addresses the accuracy of the estimate of the field DU. The field DU is not directly

\footnotetext{
${ }^{1}$ Associate Professor, Dept. of BioResource and Agricultural Engineering, and Director, Irrigation Training and Research Center, California Polytechnic State Univ., San Luis Obispo, CA 93407-0730. E-mail: sstyles@calpoly.edu

${ }^{2}$ Professor, Dept. of BioResource and Agricultural Engineering, and Chair, Irrigation Training and Research Center, California Polytechnic State Univ., San Luis Obispo, CA 93407-0730. E-mail: cburt@ calpoly.edu

${ }^{3}$ Irrigation Engineer, Irrigation Training and Research Center, California Polytechnic State Univ., San Luis Obispo, CA 93407-0730. E-mail: fgaudi@calpoly.edu

${ }^{4}$ Student, Dept. of BioResource and Agricultural Engineering, California Polytechnic State Univ., San Luis Obispo, CA 93407-0730. E-mail: saorvis@calpoly.edu
}

measured. Ignoring hose filling/emptying effects, soil differences with subsurface emitters, and unequal emitter application rates due to plant spacing variations, the field DU is indirectly estimated by combining DU components. From a practical standpoint of helping a farmer improve a field DU, it is not important to precisely know the DU-a reasonable estimate is sufficient. However, there are other cases in which it is more important to know how accurately the DU is estimated-such as when the rapid evaluations are sometimes used to verify the stated performance of a new drip system, in court cases dealing with efficiency and uniformity, and in public reporting of measured DU values.

In the ITRC rapid evaluation procedure, the required components are the pressure differences in the field $\left(\mathrm{DU}_{\mathrm{lq} \Delta p}\right)$ and the "other" causes of flow rate differences that are not related to pressure, such as plugging, manufacturing variation, and wear (combined as $\mathrm{DU}_{\mathrm{lqO} \text { ther }}$ ). The estimated field distribution uniformity of the low quarter is, therefore, calculated as

$$
\mathrm{DU}_{\mathrm{lq} \Delta q \text { global }}=\mathrm{DU}_{\mathrm{lq} \Delta p} \times \mathrm{DU}_{\mathrm{lq} \text { Other }}
$$

The DU components are computed first, rather than just measuring flows throughout the field to quantify DU, in order to identify the relative magnitude of different causes of nonuniformity. Knowing the DU, by itself, does not indicate what type of problem exists or how to improve the DU. The main goals of the ITRC rapid evaluation techniques are to ascertain the estimated DU, identify problems, and suggest possible solutions in order to assist growers in improving the DU of their fields.

A limited sampling procedure always faces the possibility that it may collect data that are unrepresentative of the complete population. This possibility increases if there are large variations in values throughout a field, and if the distribution of those values does not follow a normal, predictable pattern.

This research was conducted to determine:

- The sensitivity of the rapid evaluation results to the selection of data measurement points.

- The accuracy of the rapid technique used by ITRC to estimate global distribution uniformity by mathematically combining DU components as shown above.

ITRC's simple multiplication procedure was compared with another combination procedure by Clemmens and Solomon 


\title{
Accuracy of Global Microirrigation Distribution Uniformity Estimates
}

\author{
Stuart W. Styles
}

\author{
; Charles M. Burt
}

; Franklin Gaudi ${ }^{3}$; and Sierra Orvis ${ }^{4}$

\begin{abstract}
Emitter pressures and flow rates were systematically and extensively sampled in one drip and one microspray field. The data distributions are presented. The accuracy of rapid (limited samples) evaluation pressure sampling procedures was found to be quite good if the pressure distribution was systematic, but erroneous if the pressure distribution throughout a field was random. A simple mathematical combination of two nonuniformity components (due to pressure differences, and other causes of flow variation) provided a better estimate of overall system distribution uniformity than more complex mathematics.
\end{abstract}

\section{Introduction}

The Cal Poly Irrigation Training and Research Center (ITRC) software and procedure for the rapid evaluation of drip and microirrigation systems (Burt 2004; Burt et al. 1992) has been widely used in California by mobile laboratories, consultants, and others. Evaluation procedures developed by others are described by Burt (2004).

The ITRC rapid procedure uses limited sampling to estimate a field's distribution uniformity (DU) with about 1 person/day of field work. Programs that use this procedure are popular with farmers because the evaluations clearly show the locations and relative magnitudes of problems due to plugging and pressure differences between emitters. The evaluation procedure also defines the relative importance of various problems, plus it gives an estimate of the field DU. There is no doubt in the writers' minds that the rapid evaluation procedure provides a benefit to farmers.

The research that is reported in this paper addresses the accuracy of the estimate of the field DU. The field DU is not directly

\footnotetext{
${ }^{1}$ Associate Professor, Dept. of BioResource and Agricultural Engineering, and Director, Irrigation Training and Research Center, California Polytechnic State Univ., San Luis Obispo, CA 93407-0730. E-mail: sstyles@calpoly.edu

${ }^{2}$ Professor, Dept. of BioResource and Agricultural Engineering, and Chair, Irrigation Training and Research Center, California Polytechnic State Univ., San Luis Obispo, CA 93407-0730. E-mail: cburt@ calpoly.edu

${ }^{3}$ Irrigation Engineer, Irrigation Training and Research Center, California Polytechnic State Univ., San Luis Obispo, CA 93407-0730. E-mail: fgaudi@calpoly.edu

${ }^{4}$ Student, Dept. of BioResource and Agricultural Engineering, California Polytechnic State Univ., San Luis Obispo, CA 93407-0730. E-mail: saorvis@calpoly.edu
}

measured. Ignoring hose filling/emptying effects, soil differences with subsurface emitters, and unequal emitter application rates due to plant spacing variations, the field DU is indirectly estimated by combining DU components. From a practical standpoint of helping a farmer improve a field DU, it is not important to precisely know the DU-a reasonable estimate is sufficient. However, there are other cases in which it is more important to know how accurately the DU is estimated-such as when the rapid evaluations are sometimes used to verify the stated performance of a new drip system, in court cases dealing with efficiency and uniformity, and in public reporting of measured DU values.

In the ITRC rapid evaluation procedure, the required components are the pressure differences in the field $\left(\mathrm{DU}_{\mathrm{lq} \Delta p}\right)$ and the "other" causes of flow rate differences that are not related to pressure, such as plugging, manufacturing variation, and wear (combined as $\mathrm{DU}_{\mathrm{lqO} \text { (her }}$ ). The estimated field distribution uniformity of the low quarter is, therefore, calculated as

$$
\mathrm{DU}_{\mathrm{lq} \Delta q \text { global }}=\mathrm{DU}_{\mathrm{lq} \Delta p} \times \mathrm{DU}_{\mathrm{lq} \text { Other }}
$$

The DU components are computed first, rather than just measuring flows throughout the field to quantify DU, in order to identify the relative magnitude of different causes of nonuniformity. Knowing the DU, by itself, does not indicate what type of problem exists or how to improve the DU. The main goals of the ITRC rapid evaluation techniques are to ascertain the estimated DU, identify problems, and suggest possible solutions in order to assist growers in improving the DU of their fields.

A limited sampling procedure always faces the possibility that it may collect data that are unrepresentative of the complete population. This possibility increases if there are large variations in values throughout a field, and if the distribution of those values does not follow a normal, predictable pattern.

This research was conducted to determine:

- The sensitivity of the rapid evaluation results to the selection of data measurement points.

- The accuracy of the rapid technique used by ITRC to estimate global distribution uniformity by mathematically combining DU components as shown above.

ITRC's simple multiplication procedure was compared with another combination procedure by Clemmens and Solomon 
Table 1. Characterization of Measurements

\begin{tabular}{lcc}
\hline & \multicolumn{2}{c}{ Field } \\
\cline { 2 - 3 } Measurement & Coalinga & Huron \\
\hline Number of blocks & 4 & 6 \\
Fraction of hoses measured & One half & One third \\
Number of pressure measurements & 1,101 & 324 \\
Number of flow measurements & 1,101 & 324 \\
\hline
\end{tabular}

(1997). They recommended the following formula to combine DU components:

$$
\mathrm{DU}_{\mathrm{lq}} \approx 1-\sqrt{\left(1-\mathrm{DU}_{\mathrm{lq} 1}\right)^{2}+\left(1-\mathrm{DU}_{\mathrm{lq} 2}\right)^{2}+\frac{\left(1-\mathrm{DU}_{\mathrm{lq} 1}\right)^{2}\left(1-\mathrm{DU}_{\mathrm{lq} 2}\right)^{2}}{K_{a}^{2}}}
$$

Clemmens and Solomon (1997) showed that the value of the $K_{a}$ has no significant impact on the result until the DU components are less than about 0.80 , so a value of $K_{a}=1$ can be assumed (a typical $K_{a}$ value is 1.27 ). They also showed that the ITRC multiplication procedure gives a lower DU value than does their recommended formula, above. That demonstration used an assumed distribution of data (flows and pressures) throughout a field, based only on a regular pattern of pressure differences impacted only by friction, plus flow variation due to manufacturing variation.

Since the results of rapid evaluation techniques are calculated automatically with spreadsheets, a more complex formula is just as easy to use as a simple multiplication procedure; therefore, quite obviously the most proper equation should be used to combine components. A fundamental question addressed in this paper is whether the data distribution in a field lends itself to best using one combination procedure over another. In other words, does Eq. (1) provide an adequate description of the DU or should the ITRC rapid evaluation program use Eq. (2)? To answer this, results from the rapid evaluation computation procedure were com-

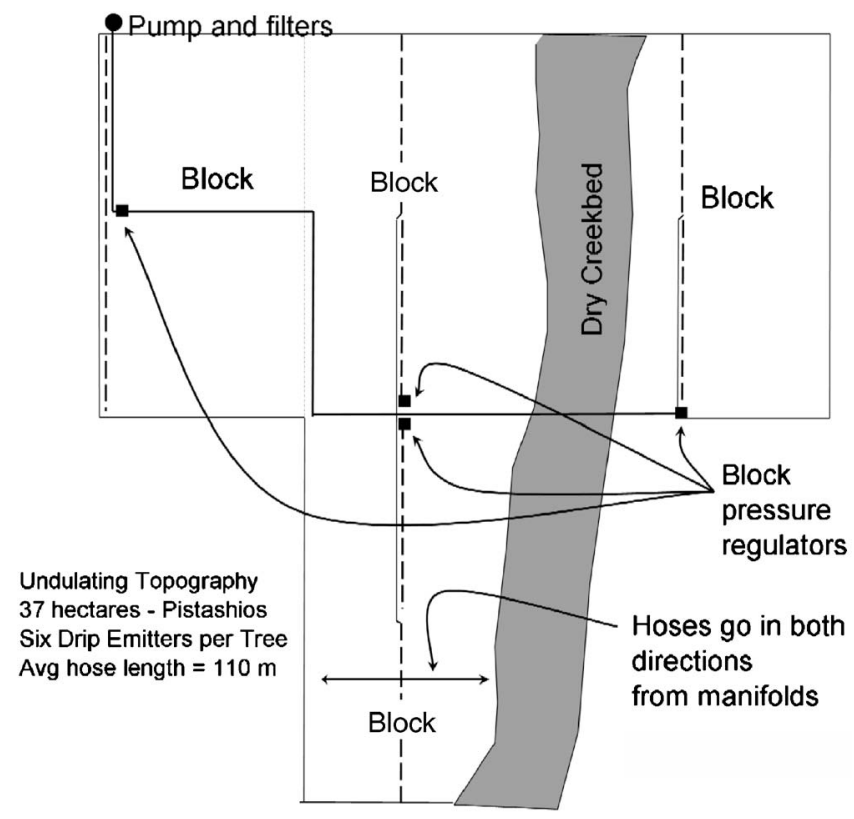

Fig. 1. Piping in the Coalinga field

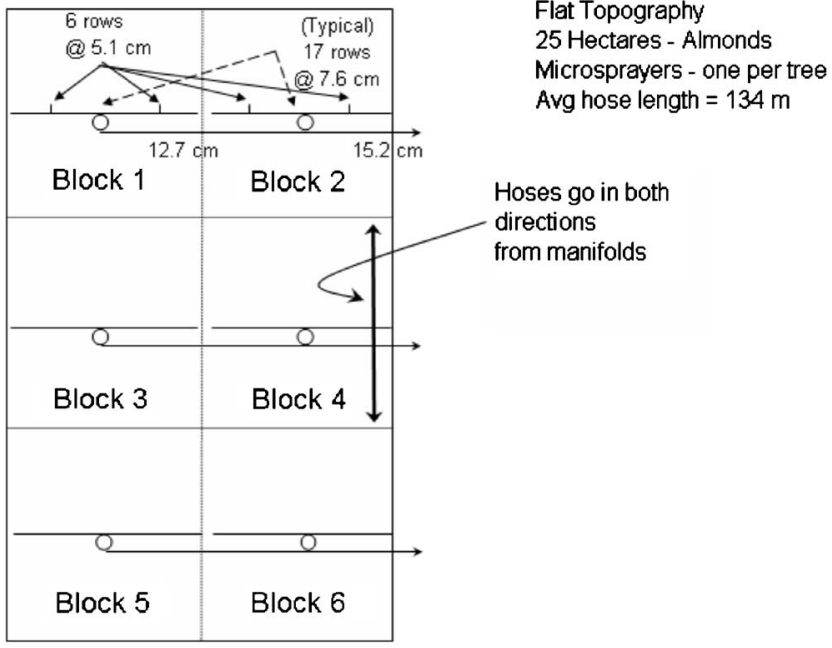

Note: This sketch is for the West half of the Field and consists of 25 hectares. The field is irrigated in 2 sections for a total of 50 hectares.

Fig. 2. Piping in the Huron field

pared to a large data set collected from the fields. It was assumed the larger data set allows the most accurate direct measurement of the DU.

\section{Methodology}

The following measurements were made in each of the fields in late summer 2004:

- Individual emitter flow rates; and

- Pressures in the hose where individual emitter flows were measured.

For both fields, pressure and flow measurements were taken systematically at nine locations (assuming hoses were long enough in both directions from the manifolds) per hose: the uphill end, three-quarter distance, middle, one-quarter distance, inlet, one-quarter distance, middle, three-quarter distance, and the downstream end of systematically selected hoses. Every third hose was selected on the Huron field, and every second hose on the Coalinga field. Again, this represents more points of evaluation than the standard ITRC rapid evaluation procedure. The buried PVC manifolds supplied hoses from about the middle of the total hose length. Measurement point information is supplied in Table 1.

Additionally, pressures and flows for three groups of 16 emitters per group were taken:

- In the middle of a hose, hydraulically nearest the pump;

- In the middle of a hose in the middle of the field; and

- At the ends of hoses, farthest hydraulically from the pump.

\section{Description of the Fields}

Two commercial fields were analyzed in the central San Joaquin Valley of California using a more thorough data collection process than the rapid evaluation procedure. One field used drip irrigation and preset automatic pressure regulators at the head of each hose; the other field used microsprayers and automatic pressure regulators at the heads of blocks. 


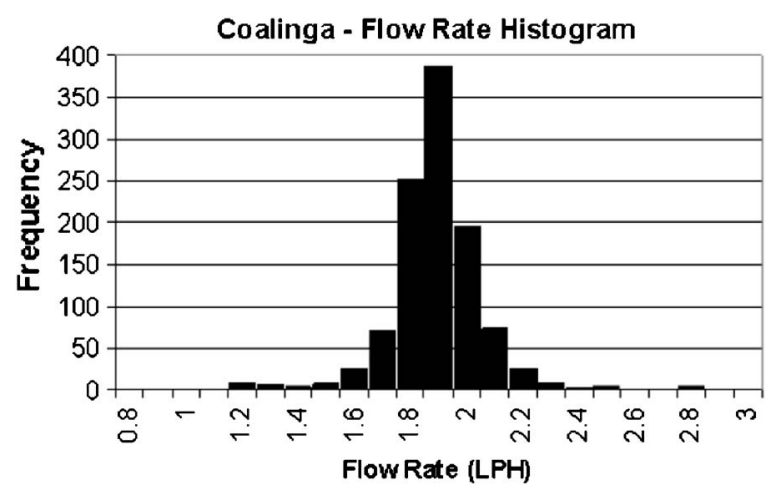

Fig. 3. Flow rate frequencies for the Coalinga field

\section{Coalinga Site Details}

The Coalinga field was a 37 ha pistachio field with drip irrigation and media filters. The tree spacing was $6.7 \times 4.9 \mathrm{~m}$. Pressure was regulated at the inlets to individual hoses; hoses and emitters had been in place for 5 years. The emitters were Netafim 2 LPH tortuous path. There were six emitters per tree. Chemicals were injected upstream of the filter. Chlorine was injected continuously. Hose ends were flushed once per year. At the time of the evaluation, about $35 \mathrm{~s}$ of hose flushing were required before the flush water appeared clear. The only water source was through the California Aqueduct. Fig. 1 shows the general field layout and piping.

\section{Huron Site Details}

The Huron field evaluated consisted of 25 ha of almonds. The tree spacing was $6.7 \times 5.5 \mathrm{~m}$. There was a 5-year-old, single-line, microsprayer system with media filters. The emitters were Olson 43.5 LPH nonrotating microsprayers, and there was one emitter per tree. Pressure was regulated at the inlets of the manifolds. The system was irrigated with water from the California Aqueduct. Fertilizer injection (UAN-32) was done upstream of the filters. Liquid chlorine was injected annually at the end of the season. Hose ends were flushed once per year. At the time of the evaluation, it was observed that about $60 \mathrm{~s}$ of hose flushing were required before the flush water looked clear. Fig. 2 shows the field layout and piping of the half of the field (61 acres) that was irrigated during the evaluation. The total field, including both sections supplied by the pump station, was 50 ha.

\section{Flow Rate Data}

Flow rates were measured by collecting all of the individual emitter discharges in buckets for a period of about $10 \mathrm{~min}$ for the Coalinga drip system and for about $5 \mathrm{~min}$ for the Huron mi-

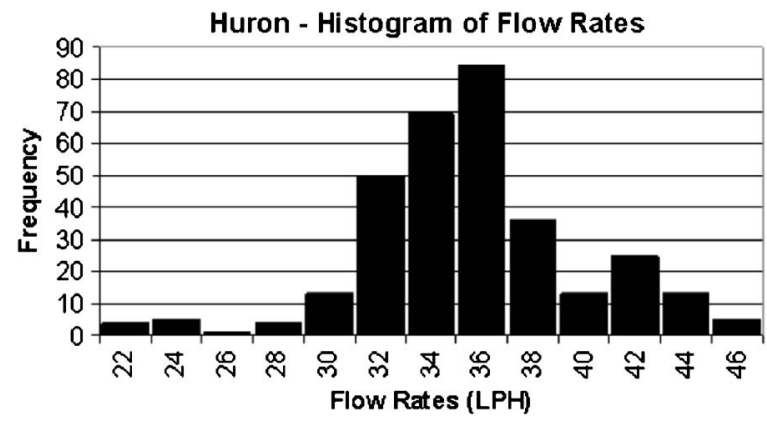

Fig. 4. Flow rate frequencies for the Huron field

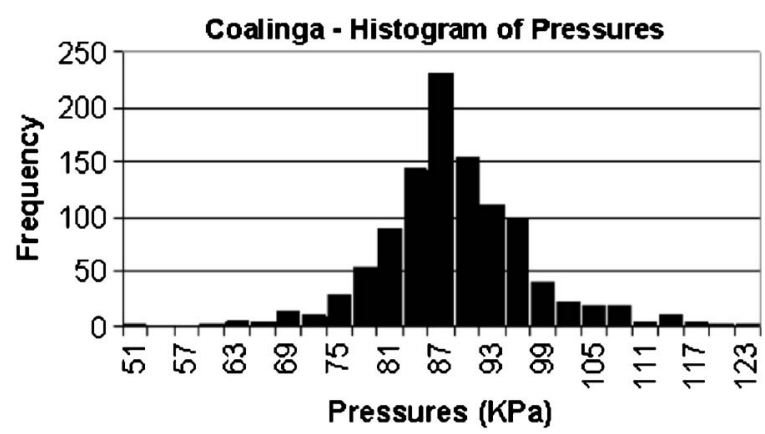

Fig. 5. Emitter pressure distribution in the Coalinga field

crospray system. Care was taken that all the water was collected in the buckets, and a stop watch was used to time individual collections. Volumes from individual buckets were measured using appropriately sized graduated cylinders with funnels to avoid spillage during the transfer of water from the buckets to the graduated cylinders. The distributions of emitter flow rates for each of the two fields are shown in Figs. 3 and 4. All of the plots of the flow rate data show a normal distribution.

\section{Emitter Pressure Data}

Pressure measurements were made with high-quality pressure gauges that were checked for accuracy with a Druck Model DPI 610 pressure testing unit. A pitot tube was attached to the end of a gauge, and the tube was inserted into a hole that was punched in the polyethylene hose. The gauge was held at ground elevation when the pressure was read.

Emitters within a group were close enough to each other that there was no noticeable pressure difference-therefore, all flow rate differences between emitters in a group were due to causes other than pressure differences. A grouping for this test is, typically, 16 emitters located close to each other and away from the start of the hose where friction loss is the highest. The average of the 16 emitter flows was determined at four pressures that spanned the pressure range observed throughout the field. These data were used to calculate the value of the emitter discharge exponent (the " $x$ " in the equation $Q=K P^{x}$, discussed later). The impact of different pressures on the DU is a function of the $P^{x}$ values.

The distributions of emitter pressures for each of the two fields are shown in Figs. 5 and 6. The flow rate and pressure distributions are not identical, in part because flow rate variations depend upon clogging and manufacturing variability as well as pressure differences. All of the plots of the pressure data show a normal distribution.

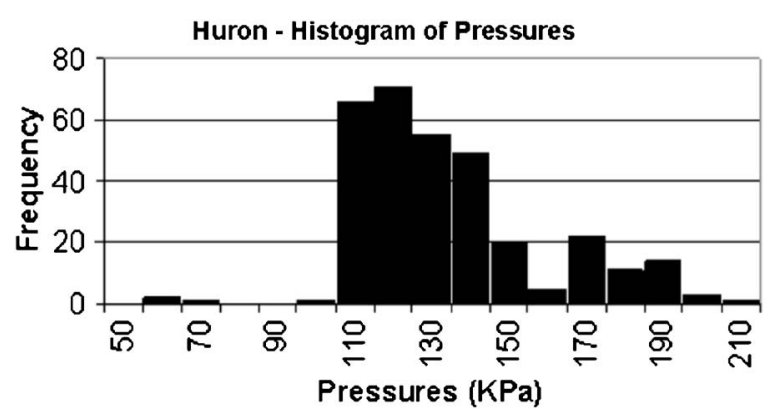

Fig. 6. Microsprayer pressure distribution in the Huron field 
Table 2. Exponent Values

\begin{tabular}{lcc}
\hline Field & $x$ & $R^{2}$ \\
Coalinga & value & value \\
Huron & 0.54 & 0.99 \\
\hline
\end{tabular}

\section{Computations}

\section{Emitter Exponents}

Emitters with tortuous paths (such as the emitters in Coalinga) and simple orifices (such as the microsprayers in Huron) have an exponent of 0.50 or very close to it. However, we have noticed that partial plugging of tortuous paths can often create exponents slightly greater than this, possibly because part of the flow path is smoothed out. A higher exponent may also be caused by other factors such as additional friction from spaghetti tubing or from lifting the sprayer to take a field measurement.

To determine the correct exponent $x$ for the existing field conditions, three groups of flow and pressure measurements were taken for each field, as described earlier. For each set group of flow rates for each field, the data were plotted and the best-fit equation of the form $Q=K P^{x}$ was determined.

The $x$ values are listed in Table 2. For Coalinga, the value of 0.54 is the average of the three exponents in the field. For Huron, the value of 0.54 is different from the theoretical value of 0.50 for an orifice, and is possibly due to the contribution of friction in the spaghetti hose. Note: If the microsprayers are raised $0.3 \mathrm{~m}$ high to place them in buckets, the computed exponent will erroneously be computed to be 0.58 rather than 0.54 unless $0.3 \mathrm{~m}$ is subtracted from the hose pressure measurement.

\section{$D U_{I q}$ Computations}

The following values were calculated for comparison purposes:

- "Actual" field distribution uniformity of the low quarter $\left(\mathrm{DU}_{\mathrm{lq}}\right)$ measured directly.

- Coefficient of variation (cv) of the DU values from the assortments of data.

- Estimated field DU (DU $\mathrm{lq}_{\mathrm{lq} \Delta \text { global }}$ ) calculated using Eq. (1). This calculation requires two components due to:

- pressure differences $\left(\mathrm{DU}_{\mathrm{lq} \Delta p}\right)$; and

- other causes ( $\left.\mathrm{DU}_{\mathrm{lq} \Delta p \text { Other }}\right)$;

- Estimated field DU (DU $\left.\mathrm{lq}_{\mathrm{lq} \Delta \text { global }}\right)$ calculated using Eq. (2).

\section{Actual Field DU}

The distribution uniformity of the low quarter is defined as

$$
\mathrm{DU}_{\mathrm{lq}}=\frac{\text { Average of low quarter } Q \text { values }}{\text { Average of all } Q \text { values }}
$$

For this comparison, the DU was based only on individual emitter flow rates, without understanding the causes of the different flow rates and without considering the number of emitters per plant. In an actual evaluation, we would have also considered nonuniformity caused by unequal drainage, by emitter spacing/flows that were not adjusted properly to match tree spacings, and the impact of the number of emitters per plant.

The samples sizes $(1,101$ in Coalinga and 324 in Huron) were large enough and systematically measured to provide a good estimate of the distribution of flows and pressures throughout the
Table 3. Characterization of the Data

\begin{tabular}{|c|c|c|c|c|c|c|}
\hline \multirow[b]{2}{*}{ Parameter } & \multicolumn{2}{|c|}{$\begin{array}{c}\text { Flow rate } \\
(\mathrm{L} / \mathrm{h})\end{array}$} & \multicolumn{2}{|c|}{$\begin{array}{c}\text { Pressure } \\
(\mathrm{kPa})\end{array}$} & \multicolumn{2}{|c|}{$P^{x}$} \\
\hline & Coalinga & Huron & Coalinga & Huron & Coalinga & Huron \\
\hline$n$ & 1,101 & 324 & 1,101 & 324 & 1,101 & 324 \\
\hline Mean & 1.9 & 34.4 & 87.1 & 128.4 & 11.1 & 13.6 \\
\hline SD & 0.579 & 4.493 & 12.755 & 26.186 & 0.89 & 1.50 \\
\hline $\mathrm{cv}$ & 0.31 & 0.13 & 0.15 & 0.20 & 0.08 & 0.11 \\
\hline $\operatorname{Avg}_{\mathrm{lq}}$ & 1.65 & 29.18 & - & - & 3.61 & 4.25 \\
\hline Actual $\mathrm{DU}_{\mathrm{lq}}$ & 0.90 & 0.85 & - & - & 0.92 & 0.882 \\
\hline
\end{tabular}

fields. The actual field $\mathrm{DU}_{\mathrm{lq}}$ is considered the same as the $\mathrm{DU}_{\mathrm{lq} \Delta p}$, computed with all of those sample flow rates in each field.

\section{Actual $\mathrm{DU}_{\mathrm{lq}}$ Component due to Pressure Differences}

This is different from the actual field DU because it only accounts for pressure differences. For each field, an actual $\mathrm{DU}_{\mathrm{lq}}$ due to pressure differences between emitters $\left(\mathrm{DU}_{\mathrm{lq} \Delta p}\right)$ was determined using the equations

$$
Q=K P^{x}
$$

and

$$
\mathrm{DU}_{\mathrm{lq} \Delta p}=\frac{\text { Average of low quarter } Q\left(P^{x}\right) \text { values }}{\text { Average of all } Q\left(P^{x}\right) \text { values }}
$$

For each of the sample locations, both the pressure and emitter flow rate were measured. For each location, the theoretical relative flow rate $\left(Q_{\mathrm{rel}}\right)$ of the emitter, using the equation $Q_{\mathrm{rel}}=P^{x}$, was used. All of those $P^{x}$ values were then used to compute the $\mathrm{DU}_{\mathrm{lq} \Delta p}$. Note that it was not necessary to use $K$ in these calculations since it is in both the numerator and the denominator. For this reason, it is not as critical to know the actual value of $K$ or how it may be affected by plugging or variations in the field.

\section{Coefficient of Variation}

For the ITRC rapid evaluations, the $\mathrm{DU}_{\mathrm{lq}}$ value is used to characterize the uniformity of irrigation systems. There are several possible variations to the DU formula, including using a numerator that is something other than the "average of the low quarter." Using a different numerator will, of course, provide a different "DU" value. Likewise, standard statistical methods could be used. An example is the coefficient of variation

$$
\mathrm{cv}=\frac{\text { Standard deviation }}{\text { Mean }}
$$

The coefficient of variation is often used to describe the uniformity of a sample of new emitters, all at the same pressure. However, it can also be used to characterize the uniformity of any sample set. Table 3 provides several characterizations of the data.

\section{Accuracy of $D U_{I q \Delta p}$ with Limited Sampling}

The ITRC rapid irrigation evaluation program uses a systematic, limited sampling technique to obtain data. This study addressed the question of whether the estimate of the DU component due to pressure variations is reasonably accurate with the limited sampling of the rapid evaluation program.

For each field, assortments of pressure values were chosen from "reasonable" locations, with reasonable defined as locations that might be selected in a field by an evaluator to satisfy the 
Table 4. Estimation of the DU Component due to Differences in Pressure

\begin{tabular}{lcc}
\hline & \multicolumn{2}{c}{ Field } \\
\cline { 2 - 3 } Measurement & Coalinga & Huron \\
\hline Actual $\mathrm{DU}_{\mathrm{lq} \Delta p}$ & 0.920 & 0.882 \\
$\begin{array}{l}\text { Average } \mathrm{DU}_{\mathrm{lq} \Delta p} \text { using ITRC rapid } \\
\text { evaluation approach }\end{array}$ & 0.911 & 0.899 \\
$\begin{array}{l}\text { Number of pressure values used for the ITRC } \\
\text { rapid evaluation approach }\end{array}$ & 64.000 & 64.000 \\
$\begin{array}{l}\text { Coefficient of variation of the DU values } \\
\text { from ITRC rapid evaluation approach }\end{array}$ & 0.028 & 0.007 \\
\hline
\end{tabular}

program definition of acceptable measurement locations. Each assortment was built from the intensive data set, to complete the two pages of data required for the rapid evaluation program. The rapid evaluation technique was designed to accurately assess the pressure distribution in the field with three combinations of pressure regulation. The three combinations were:

1. Pressure regulators at the head of each hose;

2. Pressure regulators at the heads of blocks; and

3. No pressure regulators.

For each assortment of pressure values, the $\mathrm{DU}_{\mathrm{lq} \Delta p}$ was computed (shown in Table 4). The $\mathrm{DU}_{\mathrm{lq} \Delta p}$ was lower in the Huron field than in the Coalinga field, yet limited sampling on the Huron field was more likely to give a correct estimate of the actual $\mathrm{DU}_{\mathrm{lq} \Delta p}$ in the Huron field - as evidenced by the lower $\mathrm{cv}$ of the values $(0.007$ in Huron versus 0.028 in Coalinga). The Coalinga field had undulating topography; the Huron field had a uniform plane slope. The Coalinga field used individual nonadjustable pressure regulators. The Huron field had adjustable pressure regulators at the head of each block, and the regulators were not all adjusted to the same pressure.

\section{Method for Determining $D U_{\text {Iq other }}$}

$\mathrm{DU}_{\mathrm{lq} \text { Other }}$ was calculated for each field using the three sets of flow data taken from the exponent $(x)$ calculations. Within each set of flow measurements, there were no noticeable differences in pressure. Within each group of data, the relative flow (compared to the average flow in that group) was determined for each measurement. The 48 relative flow rates were then arranged to determine

$$
\mathrm{DU}_{\text {lq Other }}=\frac{Q_{\mathrm{avg} \text { of low quarter }}}{Q_{\text {avg of all values }}}
$$

The DU values due to "other" for the two fields were Coalinga: 0.945 and Huron: 0.969 .

\section{Method for Determining $D U_{\text {Iq global }}$}

$\mathrm{DU}_{\mathrm{lq} \Delta q}$ is widely considered the actual $\mathrm{DU}_{\mathrm{lq} \text { global }}$ (neglecting any adjustment for the number of emitters per plant, unequal drainage, and problems due to tree/emitter spacings), but it does not indicate what factors contribute to the nonuniformity. Therefore, the ITRC rapid evaluation technique first determines the two DU components $\mathrm{DU}_{\mathrm{lq} \Delta p}$, and $\mathrm{DU}_{\mathrm{lq}}$ Other. These two values are then combined to estimate the system (global) $\mathrm{DU}_{\mathrm{lq} \Delta q}$ The two combination methods discussed previously were compared.

- Method 1 (used in the ITRC rapid evaluation program):

$$
\mathrm{DU}_{\mathrm{lq} \Delta q \text { global }}=\mathrm{DU}_{\mathrm{lq} \Delta p} \times \mathrm{DU}_{\mathrm{lq} \text { Other }}
$$

- Method 2 (proposed by Clemmens and Solomon 1997):

$$
\begin{aligned}
& \mathrm{DU}_{\mathrm{lq} \Delta q \text { global }}=1 \\
& -\sqrt{\left(1-\mathrm{DU}_{p}\right)^{2}+\left(1-\mathrm{DU}_{\text {Other }}\right)^{2}+\frac{\left[\left(1-\mathrm{DU}_{p}\right)^{2} \times\left(1-\mathrm{DU}_{\text {Other }}\right)^{2}\right]}{K_{a}^{2}}}
\end{aligned}
$$

All calculated values are shown in Table 5. Clearly, the data show that Method 1 (Coalinga error at $-0.3 \%$ and Huron error at $0.9 \%$ ) provides a more accurate estimate of the actual DU compared to Method 2 (average $3.5 \%$ error).

\section{Discussion}

The difference in the accuracies of the rapid evaluation technique in estimating the pressure differences in the two fields can be explained as follows:

1. The rapid evaluation technique was designed to accurately assess the normal systematic patterns of pressure variation that occur in a field. What the rapid evaluation technique did not assume was that there would be a nonsystematic, random variation of pressures throughout the Coalinga field, which was found to be due to two reasons:

a. Hose screen washers were used in the Coalinga field (and not in the Huron field). Those screens were found to be partially plugged in a random pattern-causing variations in pressure at the heads of hoses.

b. Many of the individual hose pressure regulators were defective in the Coalinga field, so their discharge pressures were random.

Pertinent points regarding the pressure distribution are:

1. The rapid evaluation technique will obtain a reasonable esti-

\begin{tabular}{|c|c|c|c|}
\hline Computation & Description & $\begin{array}{l}\text { Coalinga } \\
\text { field }\end{array}$ & $\begin{array}{l}\text { Huron } \\
\text { field }\end{array}$ \\
\hline Actual $\mathrm{DU}_{\mathrm{lq}} \Delta p$ & From all $P^{x}$ values in the field & 0.920 & 0.882 \\
\hline Actual $\mathrm{DU}_{\mathrm{lq} \Delta}$ Other & From three groups of 16 flows each & 0.945 & 0.969 \\
\hline Actual $\mathrm{DU}_{\mathrm{lq} \Delta q \text { global }}$ & From all flow values in the field & 0.872 & 0.847 \\
\hline \multirow[t]{2}{*}{ Method 1 (ITRC rapid evaluation method) } & Estimate of $\mathrm{DU}_{\mathrm{lq} \Delta q \text { global }}$ & 0.869 & 0.854 \\
\hline & Percent error of Method 1 & $-0.3 \%$ & $0.9 \%$ \\
\hline \multirow[t]{2}{*}{ Method 2, $\left(K_{a}=1.0 \text { or } K_{a}=1.27\right)^{\mathrm{a}}$} & Estimate of $\mathrm{DU}_{\mathrm{lq} \Delta q \text { global }}$ & 0.903 & 0.878 \\
\hline & Percent error of Method 2 & $3.5 \%$ & $3.7 \%$ \\
\hline
\end{tabular}
mate of the pressure distribution in a field if the pressure distribution follows an expected, systematic pattern.

Table 5. DU Low Quarter Results from Different Computations

\footnotetext{
${ }^{\mathrm{a}}$ As proposed by Clemmens and Solomon (1997).
} 
2. The rapid evaluation technique has more variability in its estimate of the pressure distribution in a field if the pressure distribution is random.

3. A random pressure distribution will be noticed by the evaluator when the evaluator examines the data. Part of the evaluation procedure also includes examination of the hose screen washer cleanliness. The evaluator can then provide a statement in the evaluation summary that the estimate of the $\mathrm{DU}_{\mathrm{lq} \Delta p}$ might not be accurate because of hardware or maintenance problems. This observation, in itself, is a benefit to the grower.

The question addressing the best way to combine DU components provided interesting results. For these two fields, Method 1 used within the rapid evaluation programs produces the best results. To fully understand if Method 1 is consistently better than Method 2 would require very expensive and detailed examination of many more fields. The writers believe that the complexity of pressure distributions and flow distributions within drip fields will lead one method to be the most accurate for some fields, and another method to be the most accurate on other fields. The accuracy of the method itself is also masked by the difficulty of precisely characterizing the whole field with limited sampling.

\section{Conclusions}

The conclusions are:

1. The pressure and flow rate sampling procedures used to estimate the DU of drip/micro irrigation systems are reasonably accurate if the pressure distribution within the field follows a systematic variation that is to be expected with a good hydraulic design and maintenance schedule.

2. The pressure sampling procedure used to estimate the DU of drip/microirrigation systems has less accuracy if there is a nonsystematic distribution of pressures at hose inlets, caused by defective hose pressure regulators, or dirty hose screen washers. However, the data are collected in such a manner as to determine that this problem exists, and the evaluator can easily point out the problem to the grower.

3. The computational procedure presently used to combine the DU components caused by variations in pressure and "other" factors (plugging, wear, manufacturing variation) gave rea- sonable results. The results of this limited study show there is no justification for changing the computation technique.

\section{Notation}

The following symbols are used in this paper:

$$
\begin{aligned}
& \mathrm{cv}=\text { coefficient of variation; } \\
& \mathrm{DU}=\text { distribution uniformity; } \\
& \mathrm{DU}_{\mathrm{lq}}=\text { computed DU of the low quarter; } \\
& \mathrm{DU}_{\mathrm{lq} \Delta p}=\text { component of DU related to pressure } \\
& \text { differences between emitters in the field; } \\
& \mathrm{DU}_{\mathrm{lq} \Delta q}=\text { computed } \mathrm{DU} \text { of the low quarter, based on } \\
& \text { flow rates; } \\
& \mathrm{DU}_{\mathrm{lq} \Delta q \text { global }}=\text { estimated field distribution uniformity of } \\
& \text { the low quarter; } \\
& \mathrm{DU}_{\mathrm{lq} \text { Other }}=\text { component of DU related to other causes } \\
& \text { (i.e., not pressure-related) of emitter flow } \\
& \text { rate differences, such as plugging, } \\
& \text { manufacturing variation, and wear; } \\
& \mathrm{DU}_{\mathrm{lq} 1}, \mathrm{DU}_{\mathrm{lq} 2}=\text { components of DU (e.g., pressure } \\
& \text { differences, or other); } \\
& K=\text { emitter discharge equation constant that } \\
& \text { accounts for units of } \mathrm{P} \text { and } \mathrm{Q} \text {; } \\
& K_{a}=\text { a factor (typical value }=1.27 \text { ) that depends } \\
& \text { upon the type of data distribution; } \\
& P=\text { pressure; } \\
& Q=\text { flow rate; } \\
& Q_{\text {rel }}=\text { relative flow rate based on } P^{x} \text {; and } \\
& x=\text { exponent of emitters. }
\end{aligned}
$$

\section{References}

Burt, C. M. (2004). "Rapid field evaluation of drip and microspray distribution uniformity." Irrig. Drain. Syst., 18, 275-297.

Burt, C. M., Walker, R., and Styles, S. W. (1992). Irrigation system evaluation manual-Revision 1992, Cal Poly Irrigation Training and Research Center, San Luis Obispo, Calif.

Clemmens, A. J., and Solomon, K. H. (1997). "Estimation of global irrigation distribution uniformity." J. Irrig. Drain. Eng., 123(6), 454-461. 